\title{
BMJ Does childhood adversity account open for poorer mental and physical health in second-generation Irish people living in Britain? Birth cohort study from Britain (NCDS)
}

\author{
Jayati Das-Munshi, ${ }^{1}$ Charlotte Clark, ${ }^{2}$ Michael E Dewey, ${ }^{1}$ Gerard Leavey, ${ }^{3}$ \\ Stephen A Stansfeld, ${ }^{4}$ Martin J Prince ${ }^{1}$
}

To cite: Das-Munshi J, Clark C, Dewey ME, et al. Does childhood adversity account for poorer mental and physical health in second-generation Irish people living in Britain? Birth cohort study from Britain (NCDS). BMJ Open 2013;3: e001335. doi:10.1136/ bmjopen-2012-001335

- Prepublication history and additional material for this paper are available online. To view these files please visit the journal online (http://dx.doi.org/10.1136/ bmjopen-2012-001335).

Received 14 October 2012 Revised 24 January 2013 Accepted 28 January 2013

This final article is available for use under the terms of the Creative Commons Attribution Non-Commercial 2.0 Licence; see http://bmjopen.bmj.com

For numbered affiliations see end of article.

Correspondence to Dr Jayati Das-Munshi; jayati.das-munshi@kcl.ac.uk

\section{ABSTRACT}

Objectives: Worldwide, the Irish diaspora experience elevated mortality and morbidity across generations, not accounted for through socioeconomic position. The main objective of the present study was to assess if childhood disadvantage accounts for poorer mental and physical health in adulthood, in second-generation Irish people.

Design: Analysis of prospectively collected birth cohort data, with participants followed to midlife.

Setting: England, Scotland and Wales.

Participants: Approximately 17000 babies born in a single week in 1958. Six per cent of the cohort were of second-generation Irish descent.

Outcomes: Primary outcomes were common mental disorders assessed at age 44/45 and self-rated health at age 42. Secondary outcomes were those assessed at ages 23 and 33 .

Results: Relative to the rest of the cohort, secondgeneration Irish children grew up in marked material and social disadvantage, which tracked into early adulthood. By midlife, parity was reached between second-generation Irish cohort members and the rest of the sample on most disadvantage indicators. At age 23, Irish cohort members were more likely to screen positive for common mental disorders (OR 1.44; $95 \% \mathrm{Cl} 1.06$ to 1.94$)$. This had reduced slightly by midlife (OR $1.27 ; 95 \% \mathrm{Cl} 0.96$ to 1.69 ). Although at age 23 second-generation cohort members were just as likely to report poorer self-rated health (OR 1.06; $95 \% \mathrm{Cl} 0.79$ to 1.43 ), by midlife this difference had increased (OR 1.25; $95 \% \mathrm{Cl} 0.98$ to 1.60 ). Adjustment for childhood and early adulthood adversity fully attenuated differences in adult health disadvantages.

Conclusions: Social and material disadvantage experienced in childhood continues to have long-range adverse effects on physical and mental health at midlife, in second-generation Irish cohort members. This suggests important mechanisms over the lifecourse, which may have important policy implications in the settlement of migrant families.

\section{ARTICLE SUMMARY}

Article focus

- In a nationally representative birth cohort from Britain, to assess the prevalence of midlife common mental disorders and poorer self-rated health in second-generation Irish respondents relative to the rest of the cohort.

- To assess the contribution of psychosocial and material disadvantage over the life-course (from childhood through to adulthood) in accounting for any observed health inequalities noted in Irish cohort members.

\section{Key messages}

- Second-generation Irish children were more likely to grow up under circumstances of marked material and social adversity relative to the rest of the cohort. By midlife, second-generation Irish cohort members were no longer disadvantaged, relative to the rest of the cohort, suggesting a degree of differential upward social mobility.

- Yet, compared with the rest of the cohort, second-generation Irish people experienced elevated relative odds of common mental disorders and poorer self-rated health at midlife. This disappeared after adjusting for childhood disadvantage.

- The findings imply that adult health disadvantages in migrant or ethnic minority groups may be 'transmitted' through exposure to childhood adversity, a factor which may be related to migrant settlement experiences.

\section{INTRODUCTION}

Four decades of research has suggested that Irish people living in Britain experience elevated mortality ${ }^{1-4}$ and morbidity, ${ }^{5}{ }^{6}$ relative to the rest of the population. Similar phenomena have been noted worldwide. ${ }^{7-9}$ These inequalities persist into second ${ }^{15}$ and later generations. ${ }^{2}{ }^{10}$ An elevated prevalence 


\section{ARTICLE SUMMARY}

Strengths and limitations of this study

- The study used mostly prospectively collected data from a nationally representative birth cohort from Britain.

- Detailed assessments of psychosocial and material circumstances in childhood and adulthood were obtained. Main outcomes were assessed using structured, validated scales (for mental health) or a standardised question around self-rated health.

- Limitations of the study include the use of parental country of birth to determine ethnicity and the lack of measures assessing the specific migration experiences of Irish cohort members, as this was a historical cohort study.

and incidence of depression and suicidality has also been noted in Irish-born and second or later generation Irish people. ${ }^{71-14}$ This is out of keeping with the assertion that over time and subsequent generations, the health of migrant groups should start to approximate to that of the receiving country. ${ }^{3}$

There have been few longitudinal studies which have examined the health of Irish people or other migrant groups using a life-course informed approach. Longitudinal studies from North America have suggested that disadvantages related to the processes of migration and settling into a new host country interact dynamically over the life-course and lead to specific health effects in migrants which diverge from the host population. ${ }^{15}$ The policy benefits of using a life-course approach are obvious; by identifying structural factors that impact on the health of second-generation Irish people from childhood through to adulthood, it may be possible to identify earlier 'intervention points', which could reduce later 'downstream' adverse health outcomes.

We analysed data from a nationally representative British birth cohort to establish if second-generation Irish people were more likely to grow up under, and live in, circumstances of material and social disadvantage over their life-course, relative to people without a parental history of migration. Our second objective was to establish if the prevalence of common mental disorders and self-rated health (a predictor for mortality ${ }^{16}$ ) would be elevated in second-generation Irish cohort members relative to the rest of the cohort, at ages 23,33 and at midlife (age 44/45). Finally, we sought to establish if disadvantage over the life-course mediated any health disparities observed at midlife (age 44/45). In particular, we wished to assess the contribution of disadvantages broken down by timing of exposure (childhood, early adulthood, midlife) and type of exposure (material disadvantage, social adversity, health-related behaviours and prior mental health/self-rated health).

\section{METHODS}

Study sample

The National Child Development Survey (NCDS) surveyed 17415 babies born during 3-9 March in 1958
(98\% of live births), and followed respondents into adulthood. Parents, teachers and medical personnel were interviewed when children were aged 7,11 and 16 . At ages 23, 33, 42 and 44/45, cohort members were interviewed. For the analysis, the 'target sample' was: children born in England, Scotland and Wales in the selected week, and children with both parents born in England, Scotland and Wales or children who had one or both parents born in Ireland or Northern Ireland.

\section{Parental migration status}

At sweeps two and three, parents reported their country of birth. Cohort members with one or both parents reporting that they were born in Ireland or Northern Ireland were classified as 'second-generation Irish'. Excluding non-responders, kappa assessing the reliability of parental responses to this question between the two sweeps was high $(\kappa=0.97)$.

\section{MEASURES \\ Childhood \\ Material and social adversity measures}

At ages 7, 11 and 16, parents of children were asked if they had experienced financial difficulties in the previous year, or lived in overcrowded housing (1+ persons/ room). Parents were asked if they had access to hot water, an indoor toilet and an indoor bathroom. At ages 11 and 16, parents reported if their child received free school meals. At age 7, health visitors assessed family difficulties; these were problems with: housing, finances, physical or mental illness/disability, learning disabilities, death, divorce, parental separation, domestic tensions, in-law conflicts, unemployment, alcoholism or any other difficulties 'affecting the child's development'.

\section{Childhood psychological health}

At ages 7 and 11, teachers rated children's emotional and behavioural health using the Bristol Social Adjustment Guide. ${ }^{17}$ At age 16, the Rutter School Behavioural Scale (Rutter-B) was completed by teachers. ${ }^{18}$ Scores on both scales were summed, square root transformed, with the top $13 \%$ indicating children who were a 'case'. ${ }^{19}$

\section{Adulthood}

Material and social adversity measures

Cohort members were asked if they lived in overcrowded housing (1+ persons/room) (ages 23, 33, 42), were unemployed $(23,33,42)$, lived in council housing (23, $33,42)$, had been homeless $(23,42)$, received benefits $(23,42)$, had access to an indoor toilet/bathroom (23), had experienced difficulties in paying bills $(33,45)$, had a telephone (33), had damp or lacked central heating in their house $(33)$, had no car $(42,45)$, had experienced financial difficulties (42) or could not afford food or clothing (45).

At age 33, cohort members rated emotional and practical social support provided from four sources of 
support. ${ }^{20}$ At age 42, cohort members reported if there was someone they could turn to for support. At age 44/45, the Close Person's Questionnaire ${ }^{21}$ assessed social support provided from the closest nominated person.

Stressful life events within the previous 6 months were assessed at age 44/45. These were: cohort member/ close relation suffering serious illnesses, injury/assault, death of parent/child/partner or close friend/relative, end of serious relationship, serious problems with a close friend/neighbour/relative, serious disappointments at work, cohort member/partner fears of losing their job, losing one's job, major financial crises, problems with the police and theft. Responses were dichotomised into experienced no stressful life events versus experienced 1+ stressful life events. At age 44/45, cohort members' job security was also enquired into.

\section{Health-related behaviours}

At ages 33 and 42, people responding in the affirmative to $\geq 1$ item on the CAGE were classed as reporting hazardous alcohol use. ${ }^{22}$ This questionnaire comprises four questions ('Have you wanted to Cut down your alcohol use lately?' 'Do you get Angry if other people suggest you should cut down your alcohol use?' 'Do you feel Guilty about the amount of alcohol you consume?' 'Have you ever needed an Eye-opener?'). ${ }^{22}$ At age 44/45, people scoring $\geq 8$ on the Alcohol Use Disorders Identification Test were classed as reporting hazardous use. $^{23}$ Cohort members also reported if they were current or previous smokers at ages 23, 33 and 42 .

\section{ADULT HEALTH OUTCOMES}

\section{Mental health}

\section{Malaise inventory}

At ages 23 and 33, cohort members completed the Malaise Inventory, which is a structured self-report tool which assesses recent psychiatric morbidity. ${ }^{24}$ Questions asked included 'Do you often feel miserable or depressed?', 'Do you wake up unnecessarily early in the morning?'. ${ }^{24}$ Scores of $\geq 8$ indicated depression. ${ }^{25}$

\section{Clinical Interview Schedule-Revised}

The Clinical Interview Schedule-Revised (CIS-R) assessed midlife common mental disorders at age $44 / 45 .^{26}$ This is a structured validated instrument administered by trained lay interviewers, where scores of $\geq 12$ indicate common mental disorders. ${ }^{26}$ In the NCDS, a shortened form of the CIS-R was used, in which sections enquiring after worry, obsessions, somatic symptoms, compulsions and physical health worries were omitted, ${ }^{27}$ thus focusing on depressive and anxiety disorders. To ensure that the results of the present analysis would be comparable to previous surveys, ${ }^{28}{ }^{29}$ an equivalent cutpoint on the abbreviated CIS-R scale was determined.

Data from the 2000 National Psychiatric Morbidity Survey (NPMS) ${ }^{29}$ and from the 2000 Ethnic Minorities Psychiatric Illness Rates in the Community Survey
(EMPIRIC) ${ }^{28}$ were used to devise an abbreviated scale of symptoms on the CIS-R, with the same items which had been omitted in the 2000 sweep of the NCDS also omitted. To determine equivalent cut-points to conventional cut-points of $11 / 12$ on the full-scale CIS-R, a linear regression of the full-scale CIS-R was performed against the abbreviated scale from the CIS-R using NPMS and EMPIRIC data. The resultant regression equation was used to predict the equivalent cut-point on the abbreviated CIS-R scale. Using this approach, a cut-point of $\geq 9$ was equivalent to the conventional cutpoint of $\geq 12$. Kappa comparing the cut-point for $11 / 12$ on the full-scale CIS-R to a cut-point of $8 / 9$ on the abbreviated scale was 0.86 for the NPMS and 0.85 for the EMPIRIC (both $\mathrm{p}<0.001$ ) data.

\section{Self-rated health}

At ages 23, 33 and 44/45, cohort members were asked: 'How would you describe your health generally?' Responses were dichotomised into 'excellent/good' versus 'fair/poor'.

\section{Statistical analysis}

STATA V.10.1 was used for analyses. ${ }^{30}$ The association of social and material adversity measures over the life-course, from childhood to adulthood, was assessed in secondgeneration Irish cohort members, relative to non-Irish cohort members. Next, the odds of screening positive for common mental disorders and poorer self-rated health, in second-generation Irish cohort members, relative to non-Irish cohort members, were assessed at 23, 33 and 44/ 45, using multivariable logistic regression. Common mental disorders and poorer self-rated health at these time points were specified as the dependent variables.

The contribution of adversity variables over the lifecourse in mediating excess risks of common mental disorders and poorer self-rated health at midlife was assessed. ${ }^{31}$ To assess mediation, three criteria needed to be fulfilled. ${ }^{31}$ First, the association of parental migration history with putative mediator was assessed using multivariable logistic regression. ${ }^{31}$ Second, the association of the putative mediator with the outcome variable (poorer self-rated health and common mental disorders at midlife) was assessed using multivariable logistic regression. ${ }^{31}$ Finally, the association of parental migration history with outcome-(either midlife common mental disorders or poorer self-rated health at midlife) was assessed in the presence of the putative mediator. ${ }^{31}$ If the coefficient for the association between parental migration history and outcome was reduced in the presence of the putative mediator, then it was presumed that the data were consistent with mediation. ${ }^{31}$

\section{Missing data}

As with any prospective survey, missing data due to attrition were a cause for concern. At ages 7, 11 and 16, the response rates were $89 \%, 88 \%, 84 \%$, and at ages 23,33 , 42 the response rates were $72 \%, 65 \%$ and $66 \% .{ }^{32}$ At age 
44/45, complete data were available for the CIS-R for 9297 individuals (which was $99 \%$ of the biomedical sample) and on self-rated health in 9115 individuals (97\% of the biomedical sample).

As missing values were likely to be missing at random, ${ }^{33}$ these values were imputed using the chained equations approach ('ICE') in STATA V.10. ${ }^{30} 34$ Imputations were conducted on all cohort members known to be alive at the time of the biomedical survey (age 44/45). Fifty imputed datasets were created using proper imputation from an imputation model in which all covariates as well as variables known to predict attrition (mother's education, region of birth, employment at 33 and social class at all sweeps) were included. ${ }^{35}$ Analyses were performed on each imputed dataset using multivariable logistic regression, and estimates were combined using Rubin's Rules. ${ }^{33}$ Wald tests assessed the strength of associations.

\section{Results}

Rates of attrition were similar in second-generation Irish respondents compared with the rest of the sample (see online supplementary table S1). In unimputed data, $90 \%$ of Irish children had a father of a manual social class background, compared with $82 \%$ of non-Irish children, at age 7. This figure remained fairly similar at midlife (age $42 ; 90 \%$ and $81 \%$, respectively), indicating that there had not been differential attrition by childhood social class over the course of follow-up. In total, 9377 cohort members provided data at age 44/45. Excluding migrants and children with parents not born in England, Scotland, Wales, Ireland or Northern Ireland, analyses were performed on 8403 individuals providing complete information on the CIS-R, and on 8243 individuals providing a response to the self-rated health at midlife question.

\section{Experiences of social adversity over the life course}

Figure 1 displays how social adversity differed for secondgeneration Irish cohort members, compared with non-Irish counterparts, over the life-course. Irish cohort members experienced marked social adversity across all childhood sweeps, relative to the rest of the cohort. These inequalities tracked into early adulthood, with differences still apparent at age 23, and to an extent, at age 33. By midlife $(42,44 / 45)$ life-course social adversity measures were equivalent in second-generation Irish cohort members relative to non-Irish cohort members.

\section{Assessment of health over the life course}

Table 1 displays differences in common mental disorders and self-rated assessments of health, assessed prospectively at ages 23, 33 and 44/45. After adjusting for gender, second-generation Irish cohort members were
Figure 1 ORs for social adversity across the life-course; second-generation Irish cohort members relative to non-Irish cohort members. Estimates on the vertical line represent no difference between the two groups. Key: *more than one person/room; **one or more family difficulties as prospectively rated by health visitor (difficulties with: housing, finances, physical illness/disability, mental illness/ neurosis, mental subnormality, death of child's mother or father, divorce/separation/desertion, domestic tension, 'in-law' conflicts, unemployment, alcoholism or any 'other serious family difficulties affecting child's development'); ${ }^{\star \star *}$ no access to at least one of the following: indoor bathroom, indoor toilet or hot water at either age 7, 11 or 16; $\sim$ periods of homelessness since last assessment.
Aoversity measures, (age)

Overcrowding*, 7

Financial difficulties, 7

Family difficulties".,

Overcrowding*; 11

Financial difficulties, 11

Free school meals, 11

Overcrowding*, 16

Financial difficulties, 16

Free school meals, 16

No access to household amenities...

Unemployed, 23

Overcrowding*: 23

Lives in social housing, 23

In receipt of benefits, 23

No sole access to indoor ba throom, 23

No sole access to indoor to ilet, 23

Difficulties paying bills, 33

Overcrowding", 33

Low emotional support, 33

Low practical support, 33

Damo in housing, 33

No household telephone, 33

Lives in social housing, 33

Unemployed, 33

No central heating. 33

Lives in social housing, 42

No household car, 42

No social support, 42

Ho social suppon,

In receipt of benefits, 42

Overcrowding*, 42

Financial difficulties, 42

Unemployed, 42

Stressful life events, 45

Difficulties paying bills, 45

Can't afford food or clothing, 45

No household car, 45

$\mathrm{V}$. insecure/ insecure in job, 45

Low confiding social support, 45

Low practical social support, 45

High negative social support, 45

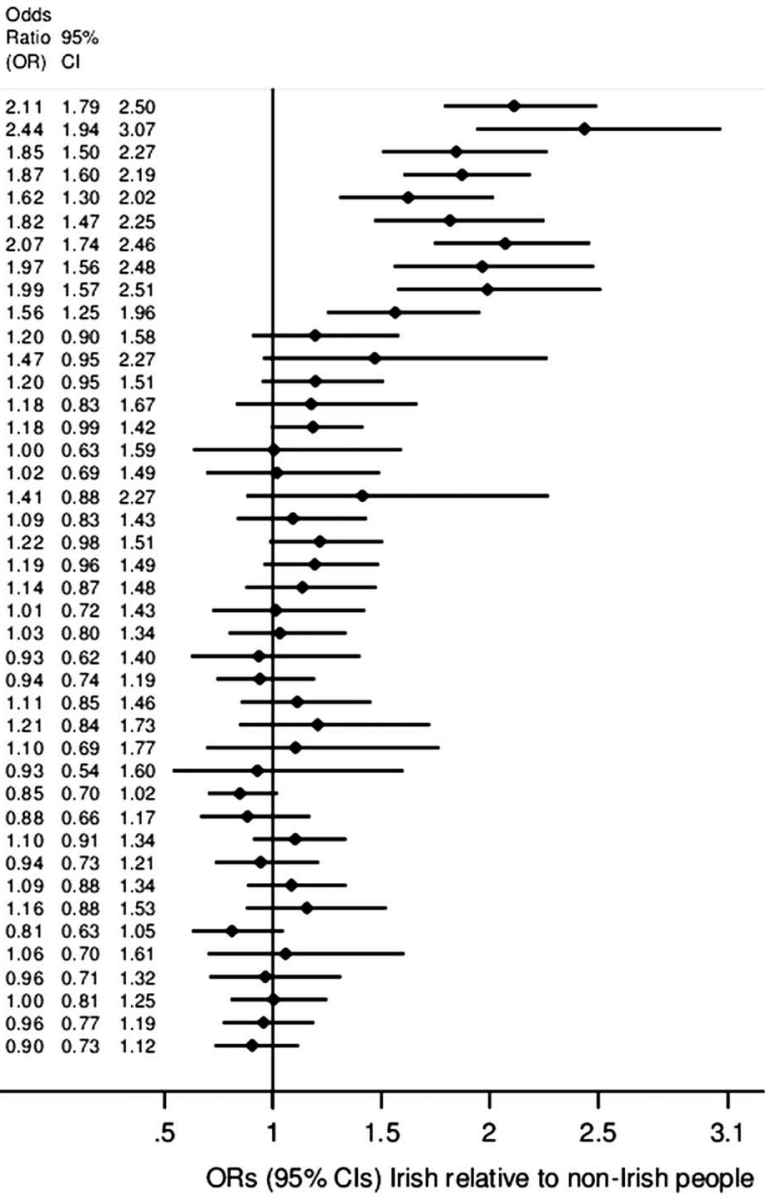


Table 1 Common mental disorders and self-rated health in second-generation Irish people across the life course

\begin{tabular}{|c|c|c|c|c|}
\hline Age & & Number of observations & OR & $(95 \% \mathrm{CI})$ \\
\hline \multicolumn{5}{|c|}{ Common mental disorders } \\
\hline \multirow[t]{2}{*}{$23^{*}$} & All other & 11036 & 1.00 & (ref) \\
\hline & Second-generation Irish & & 1.44 & 1.06 to 1.94 \\
\hline \multirow[t]{2}{*}{$33^{*}$} & All other & 9980 & 1.00 & (ref) \\
\hline & Second-generation Irish & & 1.31 & 0.94 to 1.81 \\
\hline \multirow[t]{2}{*}{$45 \dagger$} & All other & 8403 & 1.00 & (ref) \\
\hline & Second-generation Irish & & 1.27 & 0.96 to 1.69 \\
\hline \multicolumn{5}{|c|}{ Poor self-rated health } \\
\hline \multirow[t]{2}{*}{23} & All other & 11067 & 1.00 & (ref) \\
\hline & Second-generation Irish & & 1.06 & 0.79 to 1.43 \\
\hline \multirow[t]{2}{*}{33} & All other & 10045 & 1.00 & (ref) \\
\hline & Second-generation Irish & & 1.06 & 0.81 to 1.37 \\
\hline \multirow[t]{2}{*}{45} & All other & 8243 & 1.00 & (ref) \\
\hline & Second-generation Irish & & 1.25 & 0.98 to 1.60 \\
\hline
\end{tabular}

${ }^{*}$ Assessed with the Malaise inventory. $†$ Assessed with the CIS-R.

All models adjusted for gender.

CIS-R, Clinical Interview Schedule-Revised.

1.44 times more likely to screen positive for depression at age $23(95 \%$ CI 1.06 to 1.94 ; table 1$)$. Second-generation Irish cohort members continued to carry this relative excess risk throughout their life course, although the magnitude of the difference had diminished by age 33. In contrast, second-generation Irish cohort members were no more likely to report fair or poorer self-rated health in early adulthood (ages 23, 33), although by midlife (age 44/45) there was a suggestion of widening inequalities affecting the Irish group with respect to this measure (table 1 ).

\section{Midlife health in second-generation Irish cohort members}

The association of being second-generation Irish and screening positive for common mental disorders and poorer self-rated health at midlife was assessed after taking into account exposures at earlier time points (tables 2 and 3). The largest attenuation for both common mental disorders as well as poorer self-rated health at midlife was from material adversity assessed in childhood. A similar attenuation in the excess risk was seen when prospectively assessed family adversity (at age 7) was added into the models (tables 2 and 3). Material adversity at age 23 attenuated the excess risk of being Irish with poorer health at midlife, albeit to a lesser extent than childhood adversity variables. Health-related behaviours, prior mental health/self-rated health and covariates assessed from age 33 onwards did not attenuate associations of being second-generation Irish with poorer midlife health. The tables in the online repository show full associations for tables 2 and 3 .

\section{Discussion}

The findings suggest that second-generation Irish children born in the late 1950s experienced greater levels of childhood adversity than those of English, Scottish or Welsh heritage, although social and economic inequalities diminished between the two groups as the cohort entered midlife. Despite improvements in material and social conditions by adulthood, an inheritance of poorer health at midlife for second-generation Irish people was evident, relative to the rest of the cohort. Childhood material and social adversity as well as early adulthood material adversity accounted for these differences, whereas health-related behaviours and earlier psychological health/self-rated health did not.

Second-generation Irish cohort members had an elevated risk of common mental disorders in early adulthood (age 23), which had partially reduced by midlife. In contrast, for poorer self-rated health, (also a predictor for mortality ${ }^{16}$ ), although there were no differences between second-generation Irish cohort members and the rest of the cohort at earlier time points, by midlife the differences had started to become apparent.

Our findings are consistent with a large body of evidence which has shown that childhood adversity exerts long-range effects on a variety of adult health outcomes, including (but not limited to): mental health, ${ }^{37-39}$ selfrated health, ${ }^{40}$ mortality, ${ }^{41}{ }^{42}$ poorer cardiovascular health, dental health and substance abuse. ${ }^{43}$ Studies using data from birth cohorts ${ }^{43}$ (including those using data from the $\mathrm{NCDS}^{38}$ ) have shown that social class gradients in health do not emerge exclusively in adulthood but have origins in childhood, and that social and material adversity may accumulate in individuals both cross-sectionally and longitudinally, over time. ${ }^{38}$ In the present study, there was evidence to suggest that Irish cohort members were more likely than the rest of the cohort to experience an accumulation of adversity in childhood and in early adulthood; and that this, to a certain extent, accounted for a greater risk of midlife 
Table 2 Association of parental migration history (Irish vs non-Irish) with common mental disorders at midlife (age 44/45), with adjustment for putative mediators

\begin{tabular}{|c|c|c|c|}
\hline Age & Adjustments & OR & $95 \% \mathrm{Cl}$ \\
\hline \multicolumn{4}{|c|}{$\begin{array}{l}\text { Baseline model; association of parental migration history (Irish vs non-Irish) with midlife common mental disorders, after } \\
\text { adjusting for gender only: }\end{array}$} \\
\hline $44 / 45$ & Gender & 1.27 & 0.96 to 1.69 \\
\hline \multicolumn{4}{|c|}{ Models adjusting for gender+material adversity over the life-course } \\
\hline $44 / 45$ & Material adversity* & 1.28 & 0.95 to 1.72 \\
\hline 42 & Material adversity $\dagger$ & 1.28 & 0.95 to 1.72 \\
\hline 33 & Material adversity $\ddagger$ & 1.26 & 0.94 to 1.69 \\
\hline 23 & Material adversity§ & 1.18 & 0.88 to 1.57 \\
\hline $7,11,16$ & Material adversity & 1.12 & 0.84 to 1.50 \\
\hline \multicolumn{4}{|c|}{ Models adjusting for gender+health-related behaviours over the life-course } \\
\hline $44 / 45$ & Hazardous alcohol use $e^{\star *}$ & 1.25 & 0.94 to 1.67 \\
\hline 33,42 & Hazardous alcohol use†† & 1.23 & 0.92 to 1.64 \\
\hline \multicolumn{4}{|c|}{ Models adjusting for gender+previous mental health over the life-course } \\
\hline 23,33 & Adult depression $\ddagger \ddagger$ & 1.33 & 0.97 to 1.81 \\
\hline $7,11,16$ & Childhood emotional or behavioural health problems§§ & 1.21 & 0.91 to 1.62 \\
\hline \multicolumn{4}{|c|}{ Models adjusting for gender+social support over the life-course } \\
\hline $44 / 45$ & Social supportๆ & 1.30 & 0.97 to 1.73 \\
\hline 42 & Social support ${ }^{\star \star *}$ & 1.27 & 0.95 to 1.69 \\
\hline 33 & Social support††† & 1.25 & 0.94 to 1.67 \\
\hline \multicolumn{4}{|c|}{ Models adjusting for gender+stressful life events over the life-course } \\
\hline $44 / 45$ & Job insecurity $\ddagger \ddagger \ddagger$ & 1.28 & 0.96 to 1.72 \\
\hline $44 / 45$ & Stressful life events§§§ & 1.24 & 0.93 to 1.66 \\
\hline 7 & Family adversityগাগা & 1.19 & 0.89 to 1.58 \\
\hline \multicolumn{4}{|c|}{ 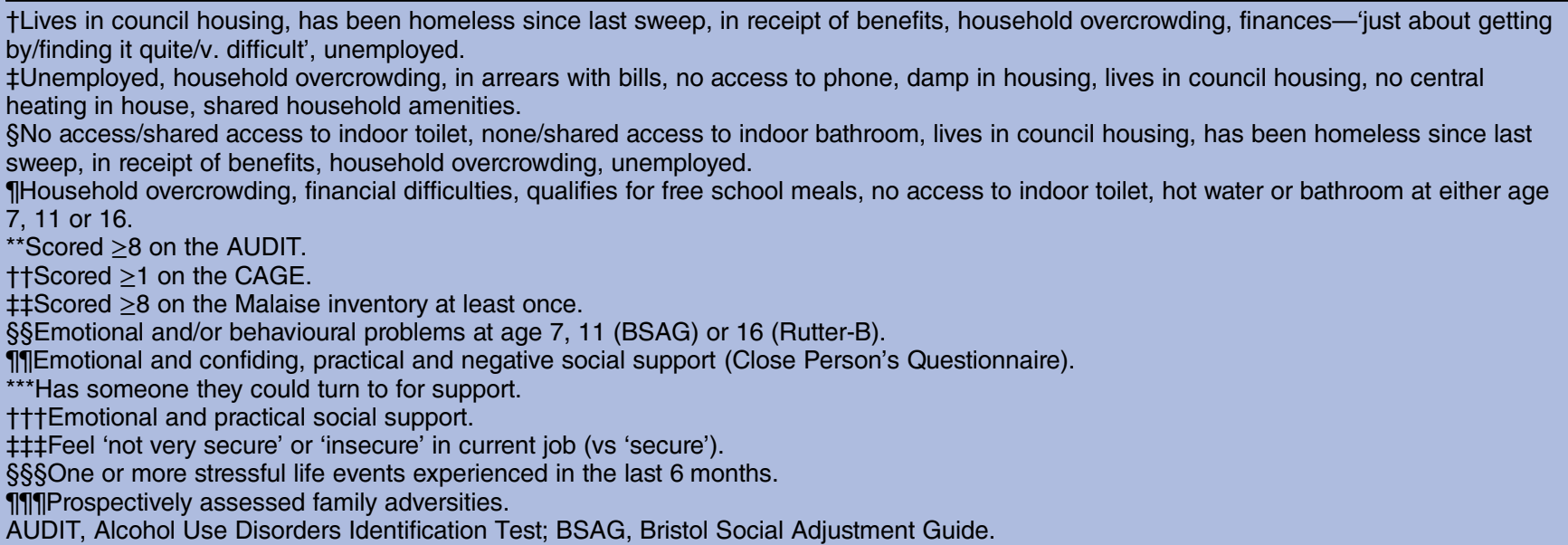 } \\
\hline
\end{tabular}

common mental disorders and poorer self-rated health, compared to the rest of the cohort. The findings of the present study are therefore in keeping with a 'sensitive period' in childhood/early adulthood which continues to adversely influence adult health many years later, ${ }^{44}$ and may be relevant in understanding previously reported adult health inequalities experienced by second-generation Irish people, despite apparent improvements in socioeconomic position across generations. ${ }^{112}$

\section{Strengths and limitations}

The data derive from a nationally representative sample from England, Scotland and Wales; therefore, the findings are generalisable to second-generation Irish people, now in midlife. Most assessments were prospective, reducing the possibility of measurement bias. The possibility of reverse causality may have been an issue, as people who had poorer health at the earlier time points may have been more likely to move into or stay in conditions of adversity. The isolated mediating effect of early life disadvantage is therefore striking, as one would have expected a larger contribution of adult social and material adversity in mediating differences.

We could not assess exposures which may have been important in understanding the specific settlement experiences of Irish people living in Britain, as these were unavailable. These might include factors relating to migration and settlement, such as the premigration health of parents, reasons and circumstances surrounding migration, ${ }^{11}$ experiences of discrimination ${ }^{11}$ and 
Table 3 Association of parental migration history (Irish vs non-Irish) with poorer self-rated health at age midlife (age 44/45), with adjustment for putative mediators

\begin{tabular}{|c|c|c|c|}
\hline Age & Adjustments & OR & $95 \% \mathrm{Cl}$ \\
\hline \multicolumn{4}{|c|}{$\begin{array}{l}\text { Baseline model; association of parental migration history (Irish vs non-Irish) with midlife poorer self rated health, after } \\
\text { adjusting for gender only: }\end{array}$} \\
\hline $44 / 45$ & Gender & 1.25 & 0.98 to 1.60 \\
\hline \multicolumn{4}{|c|}{ Models adjusting for gender+material adversity across the life-course } \\
\hline $44 / 45$ & Material adversity* & 1.27 & 0.99 to 1.64 \\
\hline 42 & Material adversity $\dagger$ & 1.27 & 0.98 to 1.64 \\
\hline 33 & Material, adversity & 1.23 & 0.96 to 1.59 \\
\hline 23 & Material adversity§ & 1.16 & 0.91 to 1.49 \\
\hline $7,11,16$ & Material adversity & 1.10 & 0.85 to 1.41 \\
\hline \multicolumn{4}{|c|}{ Models adjusting for gender+health-related behaviours across the life-course } \\
\hline $44 / 45$ & Hazardous alcohol use ${ }^{\star \star}$ & 1.24 & 0.97 to 1.58 \\
\hline 33,42 & Hazardous alcohol use†† & 1.22 & 0.95 to 1.55 \\
\hline $23,33,42$ & Life-course tobacco use $\ddagger$ & 1.23 & 0.96 to 1.57 \\
\hline \multicolumn{4}{|c|}{ Models adjusting for gender+previous mental health across the life-course } \\
\hline 23,33 & Adult depression§§ & 1.20 & 0.94 to 1.55 \\
\hline $7,11,16$ & Childhood emotional or behavioural health problemsๆी & 1.20 & 0.94 to 1.53 \\
\hline \multicolumn{4}{|c|}{ Models adjusting for gender+previous poorer self-rated health } \\
\hline $23,33,42$ & Previous poorer self-rated health & 1.35 & 1.03 to 1.77 \\
\hline \multicolumn{4}{|c|}{ Models adjusting for gender+social support across the life-course } \\
\hline $44 / 45$ & Social support*** & 1.27 & 0.99 to 1.62 \\
\hline 42 & Social support††† & 1.25 & 0.98 to 1.59 \\
\hline 33 & 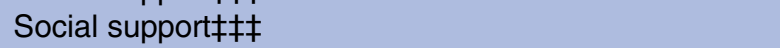 & 1.24 & 0.97 to 1.58 \\
\hline \multicolumn{4}{|c|}{ Models adjusting for gender+stressful life events across the life-course } \\
\hline $44 / 45$ & Job insecurity§§§ & 1.26 & 0.98 to 1.61 \\
\hline $44 / 45$ & Stressful life events & 1.24 & 0.97 to 1.59 \\
\hline 7 & Family adversity ${ }^{\star * * *}$ & 1.17 & 0.92 to 1.50 \\
\hline
\end{tabular}

*Difficulties in paying bills, sometimes/often can't afford food or clothing, no household car.

†Lives in council housing, has been homeless since last sweep, in receipt of benefits, household overcrowding, finances-'just about getting by/finding it quite/vs difficult', unemployed.

fUnemployed, household overcrowding, in arrears with bills, no access to phone, damp in housing, lives in council housing, no central heating in housing, shared household amenities (bathroom, shower/wash facilities, toilet, kitchen).

$\S$ No access or shared access to indoor toilet, none or shared access to indoor bathroom, lives in council housing, has been homeless, in receipt of benefits, household overcrowding, unemployed.

१Household overcrowding, financial difficulties, child qualifies for free school meals, and no access to indoor toilet, hot water or bathroom at either age 7,11 or 16 .

${ }^{* *}$ Scored $\geq 8$ on the AUDIT.

†tScored $\geq 1$ on the CAGE.

$\ddagger \ddagger$ Current or exsmoker at least once.

$\S \S$ Scored $\geq 8$ on the Malaise inventory at least once.

११|Emotional and/or behavioural problems at age 7, 11 (BSAG) or age 16 (Rutter-B).

${ }_{\star \star \star \star}$ Emotional and confiding, practical and negative social support (Close Person's Questionnaire).

$\dagger+\dagger$ Has someone they could turn to for support.

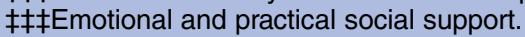

$\S \S \S F e e l s$ 'not very secure' or 'insecure' in current job (vs 'secure').

११ๆ One or more stressful life events experienced in the last 6 months.

${ }_{* \star \star \star}$ Prospectively assessed family adversities.

AUDIT, Alcohol Use Disorders Identification Test; BSAG, Bristol Social Adjustment Guide.

residential or neighbourhood context. ${ }^{45}$ Future research should endeavour to understand how these factors operate within a life-course framework.

There has been one other study from the 1970 British birth cohort which has also shown that secondgeneration Irish children were more likely to be born into disadvantage, compared to the rest of the population. ${ }^{46}$ This suggests a degree of consistency across periods and cohorts. However, we cannot be sure if period-specific effects accounted for some of the findings. In 1958, it was common for Irish people to experience overt discrimination, for example, signs reading 'No Irish Need Apply ${ }^{47}$ would have been frequently encountered when applying for employment or accommodation. By the time cohort members were aged 23 (1981), the conflict in Northern Ireland had escalated such that anti-Irish discrimination and issues relating to identity may have had a particular salience for second-generation Irish people at that time $;^{48}$ this may have contributed to the mental health inequalities noted at this age, although it was not possible to discern this from the present analysis. 
Relationship to historical context and policy implications In 1958, Irish citizens would have been subject to the recently instated 'common travel area', which enabled relatively informal migration between Ireland and Britain. Irish-born people migrating to Britain at this time took up employment in industries in which postwar labour shortages in Britain were greatest; this included the construction industry, domestic and personal industry and nursing. ${ }^{49}$ Adverse health outcomes previously noted in Irish-born migrants to Britain have been suggested to have been due to a relative lack of barrier to migration, ${ }^{3}$ alongside postmigration settlement experiences where work in transient and poorly paid employment was more likely. ${ }^{11}$ The present analysis suggests mechanisms by which such inequalities were then subsequently 'transmitted' to the next generation.

We did not have data to directly examine the childhood circumstances of Irish-born parents of cohort members. Irish-born migrants to Britain in the immediate post-war period were more likely to be shorter in height, and less well educated than both Irish people who stayed behind in Ireland, as well as English people living in England at this time. ${ }^{50}$ This might support the assertion that Irish-born migrants to Britain in the 1950s were selectively of poorer health. ${ }^{3}{ }^{50}$ This is also consistent with the assertion that parents of second-generation Irish cohort members may have experienced material adversity in their own childhoods. Although this cannot be examined directly in this dataset, findings from other cohorts have indicated that material adversity, ${ }^{51}$ as well as other risk factors for poorer adult health, such as birth weight, may 'transmit' across generations. ${ }^{52}$ It has been suggested that the economic and social resources of parents may impact on the adult health of their offspring, through the exposure of offspring to environmental factors in early life, ${ }^{51}$ or that early childhood adversity may impact not only on later adult health but also on the birth weight of future offspring ${ }^{53}$ In addition, a study of first and second-generation ethnic minority women in Britain (women of Indian, Pakistani, Bangladeshi, Black Caribbean and Black African origin) found that the mean birth weight of first and secondgeneration ethnic minority women was lower than that of white British women, with no evidence of an increase in birth weight across generations, despite it being known that these groups experience high levels of upward social mobility across generations. ${ }^{54}$ Given the links between low birth weight and later poorer adult health, such an intergenerational 'lag' in low birth weight may lead to persistent poorer health in ethnic minority groups, even if improved social circumstances had been experienced at later time points over the life-course, or across subsequent generations. Potentially, this has implications in the understanding of the 'transmission' of health inequalities in other migrant groups who may have experienced social deprivation in their childhoods, relative to people of the receiving country, and who may therefore continue to experience health inequalities in adulthood across subsequent generations, despite apparent improvement in their material circumstances.

Although by midlife, second-generation Irish people enjoyed social circumstances at parity with the rest of the cohort, an inheritance of growing up in adversity as a result of parental migration and settlement experiences has continued to influence downstream health outcomes. The relative non-specificity of childhood disadvantage in being detrimental to later health suggests important priorities for future research on the health of migrant groups now settling in Britain. Although the process of migration and settlement may mean that the experiences of relative social deprivation are transient, ${ }^{15}{ }^{55}$ tackling health inequalities in second-generation groups may mean directing concerted attention to childhood. The findings suggest the importance of considering the lifecourse in its entirety, rather than taking 'snapshot' measures of socioeconomic position at single time points, ${ }^{55}$ as it is clear that the experiences of adversity over the lifecourse have differed greatly for second-generation Irish people, relative to their non-Irish counterparts.

\section{Author affiliations}

${ }^{1}$ Health Service and Population Research Department, Institute of Psychiatry, King's College London, London, UK

${ }^{2}$ Barts and the London School of Medicine, Queen Mary University of London, London, UK

${ }^{3}$ University of Ulster, Derry-Londonderry, UK

${ }^{4}$ Centre for Psychiatry, Barts and the London School of Medicine, Queen Mary University of London, London, UK

Acknowledgements We are grateful to all collaborators for their advice in the design of the research protocol; in particular, we are grateful to Dr Mary Tilki (Federation of Irish Societies) and to Professor Amanda Sacker (Institute of Social and Economic Research) who also advised on aspects of the analysis.

Contributors JD designed the study, analysed the data and prepared the manuscript for publication. JD is the guarantor of the data and for the analysis. CC advised on aspects of the analysis and assisted in part with the analysis. CC also helped to prepare the manuscript. MED advised on statistical aspects of the analysis and helped in the preparation of the manuscript. GL advised on the study design and assisted with the literature review. GL assisted in the interpretation of results and in the preparation of the manuscript. SAS advised on the study design, assisted in the interpretation of results and advised on analytic methods. SAS assisted in the preparation of the manuscript. MJP advised on the study design, the analytic methods and in the interpretation of the results. MJP advised and helped in the preparation of the manuscript, figures and tables. All authors read and approved the final manuscript.

Funding This work was supported by a Medical Research Council training fellowship awarded to JD, grant number: G0701595/1. The funder did not play any part in design of the research protocol, data analysis or writing of the report. The analyses in this work are based wholly on analysis of data from the National Child Development Study (NCDS). The data were deposited at the UK Data Archive by the Centre for Longitudinal Studies at the Institute of Education, University of London. NCDS is funded by the Economic and Social Research Council (ESRC).

Competing interests None.

Ethics approval Access to most of the dataset for the purposes of secondary analysis was subject to the terms of an End User License (EUL) agreement. A 'special licence' for data held under 'special conditions' (as specified in section 5 of the Economic and Social Data Service (ESDS) EUL) was needed to access additional biomedical data. 
Provenance and peer review Not commissioned; externally peer reviewed.

Data sharing statement The data used for the analysis are available from the Economic and Social Data Service at http://www.esds.ac.uk/. Access to all of the data, except for biomedical data, is through an end-user license agreement. Access to biomedical data from NCDS is through a special license gained through application to ESDS.

\section{REFERENCES}

1. Harding S, Balarajan R. Patterns of mortality in second generation Irish living in England and Wales: longitudinal study. BMJ 1996;312:1389-92.

2. Harding S, Balarajan R. Mortality of third generation Irish people living in England and Wales: longitudinal study. BMJ 2001;322:466-7.

3. Marmot MG, Adelstein AM, Bulusu L. Lessons from the study of immigrant mortality. Lancet 1984;323:1455-7.

4. Abbotts J, Williams R, Smith GD. Mortality in men of Irish heritage in West Scotland. Public Health 1998;112:229-32.

5. Clucas M. The Irish health disadvantage in England: contribution of structure and identity components of Irish ethnicity. Ethnicity Health 2009;14:553-73.

6. Abbotts J, Williams R, Ford G, et al. Morbidity and Irish Catholic descent in Britain: relating health disadvantage to behaviour. Ethnicity Health 1999;4:221-30.

7. Burvill PW, McCall MG, Woodings T, et al. Comparison of suicide rates and methods in English, Scots and Irish migrants in Australia. Soc Sci Med 1983;17:705-8.

8. Kelleher CC, Lynch J, Harper S, et al. Hurling alone? How social capital failed to save the Irish from cardiovascular disease in the United States. Am J Public Health 2004;94:2162-9.

9. Rosenwaike I, Hempstead K. Differential mortality by ethnicity: foreign-born Irish, Italians and Jews in New York city, 1979-81. Soc Sci Med 1989;29:885-9.

10. Abbotts J, Williams R, Smith GD. Association of medical, physiological, behavioural and socio-economic factors with elevated mortality in men of Irish heritage in West Scotland. $J$ Public Health 1999;21:46-54.

11. Ryan L, Leavey G, Golden A, et al. Depression in Irish migrants living in London: case-control study. Br J Psychiatry 2006;188:560-6.

12. Weich S, Nazroo J, Sproston K, et al. Common mental disorders and ethnicity in England: the EMPIRIC study. Psychol Med 2004;34:1543-51.

13. Crawford MJ, Nur U, McKenzie K, et al. Suicidal ideation and suicide attempts among ethnic minority groups in England: results of a national household survey. Psychol Med 2006;35:1369-77.

14. Abbotts J, Williams R, Davey-Smith G. Mortality in men of Irish heritage in West Scotland. Public Health 1998;112:229-32.

15. Beiser M, Hou F, Hyman I, et al. Poverty, family process, and the mental health of immigrant children in Canada. Am J Public Health 2002;92:220-7.

16. DeSalvo KB, Bloser N, Reynolds K, et al. Mortality prediction with a single general self-rated health question. $J$ Gen Intern Med 2006;21:267-75.

17. Stott DH. The social adjustment of children. 3rd edn. London, England: University of London Press, 1969.

18. Rutter M. A children's behaviour questionnaire for completion by teachers. J Child Psychol Psychiatry 1967;8:1-11.

19. Ghodsian M, Fogelman K, Lambert L, et al. Changes in behaviour ratings in a national sample of children. $\mathrm{Br} J$ Soc Clin Psychol 1980;19:247-56.

20. Matthews S, Stansfeld S, Power C. Social support at age 33: the influence of gender, employment status and social class. Soc Sci Med 1999;49:133-42.

21. Stansfeld S, Marmot M. Deriving a survey measure of social support: the reliability and validity of the close persons questionnaire. Soc Sci Med 1992;35:1027-35.

22. Ewing JA. Detecting alcoholism. JAMA 1984;252:1905-7.

23. Babor TF, Higgins-Biddle JC, Saunders JB, et al. AUDIT: alcohol use disorders identification test: guidelines for use in primary care. 2nd edn. Geneva: WHO, 2001

24. Rutter M, Tizard J, Whitmore K. Education, health and behaviour. London: Longmans, 1970.

25. Centre for Longitudinal Studies Institute of Education. Teaching students quantitative methods using resources from the British Birth Cohorts. Measuring signs of psychological distress and depression: The Malaise Inventory. http://www.esds.ac.uk/doc/5805/mrdoc/pdf/ MalaiseQuestions.pdf (accessed 2011).

26. Lewis G, Pelosi AJ, Araya R, et al. Measuring psychiatric disorder in the community: a standardized assessment for use by lay interviewers. Psychol Med 1992;22:465-86.
27. Elliot J, Johnson J, Shepherd P. User guide to the biomedical survey 2002-2004 dataset. 2008; Centre for Longitudinal Studies, Bedford Group for Lifecourse \& Statistical Studies, Institute of Education, University of London.

28. Sproston J, Nazroo J. Ethnic Minority Psychiatric Illness Rates in the Community (EMPIRIC). London The Stationery Office; 2002,

Quantitative Report.

29. Singleton N, Bumpstead R, O'Brien M, et al. Psychiatric morbidity among adults living in private households, 2000. London: The Stationery Office, 2001.

30. StataCorp. Stata Statistical Software: Release 10. College Station, TX: StataCorp L.P., 2007.

31. Babyak MA. Understanding confounding and mediation. Evid Based Ment Health 2009;12:68-71.

32. Power C, Elliot J. Cohort profile: 1958 British birth cohort (National Child Development Study). Int J Epidemiol 2006;35:34-41.

33. White IR, Royston $P$, Wood AM. Multiple imputation using chained equations: issues and guidance for practice. Stat Med 30:377-99.

34. Royston P. Multiple imputation by the MICE system of chained equations. MRC Clinical Trials Unit, London.

35. Plewis I, Calderwood L, Hawkes D, et al. Changes int he NCDS and BCS70, populations and samples over time. Centre for longitudinal studies; 2004 Oct, National Child Development Study and 1970 British Cohort Study Technical Report. 1-39.

36. Clark C, Rodgers B, Caldwell T, et al. Childhood and adulthood psychological III health as predictors of midlife affective and anxiety disorders: the 1958 British birth cohort. Arch Gen Psychiatry 2007;64:668-78.

37. Clark C, Caldwell T, Power C, et al. Does the influence of childhood adversity on psychopathology persist across the lifecourse? A 45 year prospective epidemiologic study. Ann Epidemiol 2010;20:385-94.

38. Power $\mathrm{C}$, Matthews $\mathrm{S}$. Origins of health inequalities in a national population sample. Lancet 1997;350:1584-9.

39. Power C, Stansfeld SA, Matthews S, et al. Childhood and adulthood risk factors for socio-economic differentials in psychological distress: evidence from the 1958 British birth cohort. Soc Sci Med 2002;55:1989-2004.

40. Power C, Matthews S, Manor O. Inequalities in self-rated health: explanations from different stages of life. Lancet 1998;351:1009-13.

41. Galobardes B, Lynch JW, Davey-Smith G. Is the association between childhood socioeconomic circumstances and cause-specific mortality established? Update of a systematic review. $J$ Epidemiol Community Health 2008;62:387-90.

42. Galobardes B, Lynch JW, Davey-Smith G. Childhood socioeconomic circumstances and cause-specific mortality in adulthood: systematic review and interpretation. Epidemiol Rev 2004;26:7-21.

43. Poulton R, Caspi A, Milne BJ, et al. Association between children's experience of socioeconomic disadvantage and adult health: a life-course study. Lancet 2002;360:1640-45

44. Ben-Shlomo Y, Kuh D. A life course approach to chronic disease epidemiology: conceptual models, empirical challenges and interdisciplinary perspectives. Int J Epidemiol 2002;31:285-93.

45. Das-Munshi J, Becares L, Dewey ME, et al. Understanding the effect of ethnic density on mental health: multi-level investigation of survey data from England. BMJ 2010;341:c5367.

46. Das-Munshi J, Clark C, Dewey M, et al. Born into adversity; the intergenerational transmission of psychological morbidity in second generation Irish children living in Britain. J Epidemiol Community Health 2011;65:A31-2.

47. Ryan L. Family matters: (e)migration, familial networks and Irish women in Britain. Sociol Rev 2004;52:351-70.

48. Hickman MJ, Morgan S, Walter B, et al. The limitations of whiteness and the boundaries of Englishness: second-generation Irish identifications and positionings in multiethnic Britain. Ethnicities 2005;5:160-82.

49. Winston N. Between two places: a case study of Irish-born people living in England. Dublin: The Irish National Committee of the European Cultural Foundation, 2000.

50. Delaney L, Fernihough A, Smith JP. Working paper: Exporting poor health; The Irish in England, in RAND Labor and Population working paper series. University College Dublin, Geary Institute and School of Economics, RAND Corporation, 2011.

51. Osler M, Andersen A-MN, Lund R, et al. Effect of grandparent's and parent's socioeconomic position on mortality among Danish men born in 1953. Eur J Public Health 2005;15:647-51.

52. Klebanoff MA, Schulsinger C, Mednick BR, et al. Preterm and small-for-gestational-age birth across generations. Am J Obstetr Gynecol 1997;176:521-6.

53. Lawlor DA, Davey Smith G, Ebrahim S. Association between leg length and offspring birthweight: partial explanation for the 
trans-generational association between birthweight and cardiovascular disease: findings from the British Women's Heart and Health Study. Paediatr Perinat Epidemiol 2003;17:148-55.

54. Harding S, Rosato M, Cruickshank J. Lack of change in birthweights of infants by generational status among Indian, Pakistani,
Bangladeshi, Black Caribbean, and Black African mothers in a British cohort study. Int J Epidemiol 2004;

33:1279-85.

55. Das-Munshi J, et al. Migration, social mobility and common mental disorders: critical review of the literature and meta-analysis. Ethnicity \& Health 2012;17:17-53. 